Emergence of a broad repertoi re of GAD65- speci fic T-cel I s in type 1 di abet es pat i ent $s$ wi th graf $t$ dysfunct i on af ter al I ogenei $c$ i sl et $t r$ anspl ant at i on.

\begin{tabular}{|c|c|}
\hline 著者 & $\begin{array}{l}\text { Chuj o Dai suke, Foucat Emile, Taki ta Mri hi to, } \\
\text { I t oh Takeshi, Sugi mot o Koj i, Shi noda Nasayuki, } \\
\text { Yagi Kuni masa, Yamagi shi Nasakazu, Tamur a } \\
\text { Yoshi ko, Yu Li pi ng, Nazi ruddi n Bashoo, Levy } \\
\text { Marl on F., Ueno Hi deki, Mat sumbt o Shi ni chi }\end{array}$ \\
\hline $\begin{array}{l}\text { j our nal or } \\
\text { publ i cat } i \text { on } \mathrm{title}\end{array}$ & Cel I Tr anspl ant at i on \\
\hline vol une & 21 \\
\hline number & 12 \\
\hline page $r$ ange & 27832795 \\
\hline year & 2012-09-01 \\
\hline URL & ht t p: //hdl . handl e. net /2297/48419 \\
\hline
\end{tabular}




\title{
Emergence of a Broad Repertoire of GAD65-Specific T-Cells in Type 1 Diabetes Patients With Graft Dysfunction After Allogeneic Islet Transplantation
}

\author{
Daisuke Chujo,* Emile Foucat,* Morihito Takita, $\uparrow$ Takeshi Itoh, $\dagger$ Koji Sugimoto, $\dagger$ \\ Masayuki Shimoda, $\uparrow$ Kunimasa Yagi, $\$$ Masakazu Yamagishi, $\$$ Yoshiko Tamura, $§$ Liping Yu,, $\mathbb{I}$ \\ Bashoo Naziruddin, $\S$ Marlon F. Levy, $\uparrow \S$ Hideki Ueno,* and Shinichi Matsumoto* ${ }^{* 1}$ \\ *Baylor Institute for Immunology Research, Dallas, TX, USA \\ $\dagger$ Baylor Research Institute Islet Cell Laboratory, Dallas, TX, USA \\ $\ddagger$ Division of Cardiovascular Medicine, Kanazawa University Graduate School \\ of Medical Science, Kanazawa, Japan \\ $\S$ Annette C. and Harold C. Simmons Transplant Institute, Dallas, TX, USA \\ I[Barbara Davis Center for Childhood Diabetes, \\ University of Colorado Health Science Center, Aurora, CO, USA
}

\begin{abstract}
Islet transplantation is one of the most promising therapies for type 1 diabetes (T1D). A major issue in islet transplantation is the loss of graft function at late phase. Several studies suggested the involvement of isletspecific T-cells in such islet graft dysfunction. In this study, we investigated the breadth and type of glutamic acid decarboxylase 65 (GAD65)-specific T-cells in T1D patients after allogeneic islet transplantation. Peripheral blood mononuclear cells (PBMCs) were obtained from islet-transplanted T1D patients during insulinindependent period and cultured for 7 days with pools of GAD65 overlapping peptides in the presence of IL-2. Cytokine secretion profiles of peptide-reactive T-cells were analyzed after a short-term restimulation with the same peptides by a multiplex bead-based cytokine assay and by an intracytoplasmic cytokine detection assay. Robust GAD65-specific CD4 ${ }^{+}$and $\mathrm{CD}^{+} \mathrm{T}$-cell responses were detected in patients who eventually developed chronic graft dysfunction. Multiple GAD65 peptides were found to induce specific T-cell responses in these patients, indicating that the repertoire of GAD65-specific T-cells was broad. Furthermore, GAD65-specific $\mathrm{CD}^{+} \mathrm{T}$-cells were composed of heterogeneous populations, which differentially expressed cytokines including IFN- $\gamma$ and type 2 cytokines, but not IL-10. In contrast, patients who showed only marginal GAD65-specific T-cell responses maintained substantially longer graft survival and insulin independence. In conclusion, our study suggests that the emergence of islet-specific T-cells precedes the development of chronic graft dysfunction in islet-transplanted patients. Thus, our observations support the hypothesis that these islet-specific T-cells contribute to the development of chronic islet graft dysfunction.
\end{abstract}

Key words: Islet transplantation; Type 1 diabetes (T1D); Graft dysfunction; Glutamic acid decarboxylase 65 (GAD65); T-cells

\section{INTRODUCTION}

Type 1 diabetes (T1D) is caused by autoimmunitybased destruction of insulin-producing islet $\beta$-cells (3, 10,24). While a majority of T1D patients display serum antibodies specific for islet antigens, including glutamic acid decarboxylase 65 (GAD65), insulinoma antigen-2 (IA-2), and insulin, islet-specific T-cells appear to play a major role in the development of T1D $(25,39)$. GAD65 is one of the best characterized among islet antigens $(4,17,23,36)$, and mouse studies demonstrate that GAD65-specific T-cells are directly associated with the pathogenesis of T1D $(35,38,42)$. Consistently, T1D patients have been found to display GAD65-specific $\mathrm{CD}^{+}$and $\mathrm{CD}^{+}$T-cells in blood (7).

Islet transplantation is one of the most promising therapies for T1D. Approximately $70 \%$ of patients achieve insulin independence after islet transplantation. However, only approximately $50 \%$ of those patients maintain insulin independence for more than 2 years (1) and only $10 \%$ for more than 5 years (27). Therefore, loss of islet graft function at late phase is a current major issue in islet transplantation. In

Received September 23, 2011; final acceptance February 16, 2012. Online prepub date: September 7, 2012.

${ }^{1}$ Current address: National Center for Global Health and Medicine, Islet Transplantation Project, 1-21-1 Toyama Shinjuku-ku, Tokyo 162-8655, Japan. Address correspondence to Hideki Ueno, M.D., Ph.D., Baylor Institute for Immunology Research, 3434 Live Oak Street, Dallas, TX 75204, USA. Tel: +1-214-820-9917; Fax: +1-214-820-4813; E-mail: HidekiU@ baylorhealth.edu 
acute islet graft rejection, T-cells recognizing alloantigens (i.e., alloreactive T-cells) expressed by transplanted islets appear to be instrumental. In contrast, islet-specific T-cells rather than alloreactive T-cells have been suggested to play a major role in chronic islet graft dysfunction. Several studies showed that patients who lost islet functions after transplantation display islet antigen-specific T-cells in blood $(12,22,26)$. These conclusions were drawn either by analyzing T-cell proliferation in response to stimulation with isletspecific proteins in vitro or by staining peripheral blood mononuclear cells (PBMCs) with islet-specific human leukocyte antigen (HLA) class I tetramers. However, the breadth and the type of islet-specific T-cells emerging after islet transplantation remain largely unknown.

In this study, we analyzed GAD65-specific T-cell responses in T1D patients who received islet transplantation. To determine the breadth and type of GAD65specific T-cells, we took advantage of overlapping peptide library, which permits simultaneous detection of both $\mathrm{CD}^{+}$and $\mathrm{CD} 8^{+}$antigen-specific T-cell responses in cultures. We show that a broad repertoire of GAD65specific T-cells was present in patients who eventually developed graft dysfunction. GAD65-specific T-cells in these patients contained interferon (IFN) $-\gamma$-secreting type 1 helper T-cells (Th1 cells) as well as interleukin (IL)-13-producing type 2 helper T-cells (Th2 cells) and IFN- $\gamma$-producing $\mathrm{CD}^{+}$T-cells. In contrast, GAD65specific T-cells were virtually absent in patients who have maintained long-term graft survival.

\section{MATERIALS AND METHODS}

\section{Patients}

Six T1D patients who received allogeneic islet transplantation participated in this study. Islet isolation and transplantation were performed as previously described $(19,20)$. Three patients received daclizumab, and the other three received anakinra and etanercept as anti-inflammatory therapy and thymoglobulin for the induction therapy of immunosuppression (20). All of six patients received tacrolimus with mycophenolate mofetil (MMF) for the maintenance therapy of immunosuppression (20). All the patients participating in this study signed informed consent forms from an institutional review board-approved protocol (project No. 008-095). In this study, we defined "chronic graft dysfunction" as the condition where insulin injection becomes required after an insulin-independent period due to the deterioration of endogenous insulin secretion.

\section{Monitoring Islet Graft Function}

A secretory unit of islet transplant objects (SUITO) index, which reflects the functional engrafted islet mass $(18,21)$, was used to assess the islet graft function. The formula of the SUITO index is as follows: fasting C-peptide ( $\mathrm{ng} / \mathrm{ml})$ / [fasting blood glucose $(\mathrm{mg} / \mathrm{dl})-63$ ] $\times 1,500$. A SUITO index of 100 reflects $100 \%$ pancreatic $\beta$-cell function in a healthy person. A SUITO index of more than 26.0 was shown to be associated with insulin independence $(18,21)$.

\section{Blood Samples}

Peripheral blood samples were obtained from the islet transplanted recipients at various time points. PBMCs were isolated by density gradient centrifugation, using Ficoll-Paque PLUS (GE-Healthcare Bio-Sciences, Piscataway, NJ) from sodium-heparinized blood within $24 \mathrm{~h}$ after sampling. Serum was stored at $-80^{\circ} \mathrm{C}$.

\section{Autoantibody Measurement}

Anti-GAD65 antibody (GAD65-Ab) in serum was measured by a combined radiobinding assay at the Barbara Davis Center for Childhood Diabetes, University of Colorado, Denver, as previously described $(37,40)$. Briefly, labeled recombinant GAD65 ( $\left.{ }^{3} \mathrm{H}-\mathrm{GAD} 65\right)$ was produced by in vitro transcription/translation. The radioassay was performed on a 96-well filtration plate (Fisher Scientific, Loughborough, UK), and radioactivity was counted on a TopCount 96-well plate $\beta$-counter (PerkinElmer Life Sciences, Wilmington, DE). Serum antibody titers were indicated as an index of radioactivity. The upper limits of normal, nondiabetic subjects' sera were established as the 99th percentile value in healthy controls.

\section{Overlapping Peptide Libraries}

A 15-mer overlapping peptide library was designed to cover the entire 585 amino acids sequence of GAD65 with four amino acids lagging (144 peptides, BioSynthesis, TX) (Table 1). Peptides were dissolved at $10 \mathrm{mM}$ with $50 \%$ acetonitrile (Sigma-Aldrich Co., St. Louis, MO) and pooled into clusters containing 10-11 peptides, which resulted in the generation of 14 peptide clusters (C1-C14) (Table 2). Peptide clusters were kept frozen at $-80^{\circ} \mathrm{C}$.

\section{Cell Culture}

PBMCs were resuspended at a concentration of $2.5 \times 10^{6}$ cells/ml in complete medium [CM; RPMI 1640 medium (GIBCO, Carlsbad, CA) supplemented with $1 \%$ L-glutamine (Sigma), $1 \%$ penicillin/streptomycin (Sigma), $50 \mu \mathrm{M} 2-\beta$-mercaptoethanol (Sigma), $1 \%$ sodium pyruvate (Sigma), 1\% nonessential amino acid (Sigma), and 10\% heat-inactivated human AB serum (Gemini Bio-Products, Sacramento, CA)]. The cell viability was examined with $0.4 \%$ trypan blue solution (Sigma) and was always $>95 \%$. Cells $\left(5 \times 10^{5}\right.$ cells per well) were cultured in a 96 -well deep well plate in the presence of GAD65 peptide clusters $(10 \mu \mathrm{M}$ each peptide). Equal amount of peptide diluent was used as a negative control. Staphylococcal 
Table 1. Layout of GAD65 Overlapping Peptide Library

\begin{tabular}{lcl}
\hline Peptide \# & AA\# & \multicolumn{1}{c}{ AA Sequence } \\
\hline 1 & $1-15$ & MASPGSGFWSFGSED \\
2 & $5-19$ & GSGFWSFGSEDGSGD \\
3 & $9-23$ & WSFGSEDGSGDSENP \\
4 & $13-27$ & SEDGSGDSENPGTAR \\
5 & $17-31$ & SGDSENPGTARAWCQ \\
6 & $21-35$ & ENPGTARAWCQVAQK \\
7 & $25-39$ & TARAWCQVAQKFTGG \\
8 & $29-43$ & WCQVAQKFTGGIGNK \\
9 & $33-47$ & AQKFTGGIGNKLCAL \\
10 & $37-51$ & TGGIGNKLCALLYGD \\
$\cdot$ & $\cdot$ & \\
$\cdot$ & $\cdot$ & \\
$\cdot$ & $\cdot$ & \\
135 & $537-551$ & MMEYGTTMVSYQPLG \\
136 & $541-555$ & GTTMVSYQPLGDKVN \\
137 & $545-559$ & VSYQPLGDKVNFFRM \\
138 & $549-563$ & PLGDKVNFFRMVISN \\
140 & $553-567$ & KVNFFRMVISNPAAT \\
141 & $557-571$ & FRMVISNPAATHQDI \\
142 & $561-575$ & ISNPAATHQDIDFLI \\
143 & $565-579$ & AATHQDIDFLIEEIE \\
144 & $569-583$ & QDIDFLIEEIERLGQ \\
\hline AA & $571-585$ & IDFLIEEIERLGQDL \\
\hline
\end{tabular}

AA, amino acid.

Table 2. Layout of GAD65 Peptide Clusters

\begin{tabular}{lccc}
\hline Cluster \# & Peptide \# & Cluster \# & Peptide \# \\
\hline C1 & $1-10$ & C8 & $71-80$ \\
C2 & $11-20$ & C9 & $81-90$ \\
C3 & $21-30$ & C10 & $91-100$ \\
C4 & $31-40$ & C11 & $101-111$ \\
C5 & $41-50$ & C12 & $112-122$ \\
C6 & $51-60$ & C13 & $123-133$ \\
C7 & $61-70$ & C14 & $134-144$ \\
\hline
\end{tabular}

C, peptide cluster.

enterotoxin B (SEB; $0.1 \mu \mathrm{g} / \mathrm{ml})$ was used as a positive control. To expand the antigen-specific T-cells, $100 \mathrm{U} / \mathrm{ml}$ recombinant human IL-2 [TECIN (Teceleukin); Roche] was added to the culture at day 2 of culture. Cells were harvested on day 7 and split into two cultures for intracytoplasmic cytokine detection assay and cytokine secretion assay.

\section{Intracytoplasmic Cytokine Detection}

Cultured PBMCs were resuspended with $\mathrm{CM}$ at a concentration of $1.0 \times 10^{6}$ cells $/ \mathrm{ml}$ and restimulated with the same GAD65 peptide clusters $(10 \mu \mathrm{M}$ per peptide) for 6 h. Brefeldin A (Golgi Plug ${ }^{\mathrm{TM}}$; BD Biosciences, San Jose,
CA) was added for the last $4 \mathrm{~h}$ of culture. After surface staining, cells were fixed, permeabilized, and then stained for intracytoplasmic cytokines. CD8 peridinin chlorophyll protein complex (PerCP; SK1) was obtained from BD Pharmingen. CD3 allophycocyanin (APC)-Alexa Fluor 750 (S4.1) and CD4 phycoerythrin-cyanine 7 (PE-Cy7; S3.5) were obtained from Invitrogen. IL-13 APC (JES10-5A2) and IFN- $\gamma$ Pacific Blue (4S.B3) were obtained from Biolegend. Stained cells were analyzed with FACSCantoII ${ }^{\mathrm{TM}}$ flow cytometer (BD Biosciences), and the data were analyzed by the software FLOWJO (Tree Star, Inc., Ashland, OR).

\section{Cytokine Secretion Assay}

Cultured PBMCs were resuspended with CM containing carboxyfluorescein succinimidyl ester (CFSE) at a concentration of $1.0 \times 10^{6}$ cells $/ \mathrm{ml}$ and restimulated with the same GAD65 peptide clusters $(10 \mu \mathrm{M}$ per peptide) for $24 \mathrm{~h}$. Secreted cytokine levels [IL-5, IL-10, IL-13, IL-17A, IL-21, tumor necrosis factor (TNF)- $\alpha$, and IFN- $\gamma$ ] were measured by a multiplex bead-based cytokine assay (BIO-RAD). Data were analyzed using the software GraphPad PRISM. In some figures, for the visualization of the secreted cytokine levels, the data were transformed into a heat-map format indicating the fold increase from the background.

\section{RESULTS}

\section{Clinical Outcomes of Islet Transplantation}

Patients and clinical characteristics were shown in Table 3. Serum C-peptide was undetectable in Pts. \#1-5 before transplantation, indicating that pancreatic $\beta$-cell function was totally abolished. Five patients (Pts. \#1-5) achieved insulin independence, whereas one patient (Pt. \#6) experienced immediate islet graft loss (Table 3). As of June 2011, Pts. \#1, \#2, and \#3 have been maintaining a high SUITO index and insulin independence for 155,78 , and 114 weeks posttransplant, respectively (Table 3, Fig. 1). In contrast, Pts. \#4 and \#5 did not maintain their SUITO index at greater than 26 and restarted insulin injection at 37 and 46 weeks after the second islet transplantation, respectively. In Pt. \#6, while the SUITO index reached 35.0 at 1 week posttransplantation, the index dropped to 6.3 at week 2. This patient received $\sim 10,000 \mathrm{IEQ} / \mathrm{kg}$ islets, and thus, the rapid graft failure was unlikely due to graft insufficiency.

\section{Serum GAD65-Ab Titers in Islet Transplantation}

To analyze whether chronic graft dysfunction is associated with the increase of GAD65-specific antibody titers, we measured serum GAD65-Ab titers before and after islet transplantation (Table 3, Fig. 2). Only Pt. \#4, who developed chronic graft dysfunction, displayed GAD65-Ab before transplantation (Table 3) 
Table 3. Clinical Characteristics of the Patients Who Received Islet Transplantation

\begin{tabular}{|c|c|c|c|c|c|c|}
\hline & \multicolumn{3}{|c|}{ Long-Term Graft Survival } & \multicolumn{3}{|c|}{ Graft Dysfunction } \\
\hline & Pt. \#1 & Pt. \#2 & Pt. \#3 & Pt. \#4 & Pt. \#5 & Pt. \#6 \\
\hline \multicolumn{7}{|l|}{ Pretransplantation } \\
\hline Age, gender & $55 y, F$ & $38 \mathrm{y}, \mathrm{F}$ & $53 y, F$ & $55 y, F$ & $51 \mathrm{y}, \mathrm{F}$ & $35, \mathrm{~F}$ \\
\hline Disease duration (years) & 43 & 33 & 44 & 16 & 38 & 25 \\
\hline $\mathrm{BMI}\left(\mathrm{kg} / \mathrm{m}^{2}\right)$ & 23.4 & 20.7 & 27.9 & 29.9 & 26.6 & 21.2 \\
\hline HLA-DR & 4,8 & 3,4 & 4,17 & 3,13 & 4,13 & 4,17 \\
\hline GAD65 antibody & - & - & - & + & - & - \\
\hline C-peptide (ng/ml) & 0.0 & 0.0 & 0.0 & 0.0 & 0.0 & 0.3 \\
\hline SUITO index & 0.0 & 0.0 & 0.0 & 0.0 & 0.0 & 5.6 \\
\hline $\operatorname{HbA1c}(\%)$ & 8.3 & 8.4 & 9.4 & 8.3 & 7.4 & 6.2 \\
\hline \multicolumn{7}{|l|}{ Posttransplantation } \\
\hline Transplanted islets (IEQ/kg) & 28,114 & 18,275 & 12,010 & 12,096 & 13,496 & 9,367 \\
\hline \multicolumn{7}{|l|}{ Immunosuppression } \\
\hline Induction therapy & Dac/Eta & ATG/Ana/Eta & ATG/Ana/Eta & Dac/Eta & Dac/Eta & ATG/Ana/Eta \\
\hline Maintenance therapy & Tac/MMF & Tac/MMF & Tac/MMF & Tac/MMF & Tac/MMF & Tac/MMF \\
\hline C-peptide $(\mathrm{ng} / \mathrm{ml})^{\mathrm{a}}$ & 2.4 & 1.3 & 1.3 & 3.2 & 1.2 & 0.1 \\
\hline SUITO index ${ }^{a}$ & 64.3 & 28.3 & 30.5 & 77.4 & 20.2 & 4.3 \\
\hline $\operatorname{HbA} 1 \mathrm{c}(\%)^{\mathrm{a}}$ & 5.4 & 5.5 & 6.2 & 5.9 & 6.6 & 5.9 \\
\hline Insulin independence (period) & 155 weeks+ & 78 weeks+ & 114 weeks+ & 37 weeks & 46 weeks & 0 week \\
\hline Still insulin independent & Yes & Yes & Yes & No & No & No \\
\hline
\end{tabular}

Dac, daclizumab; Eta, etanercept; ATG, thymoglobulin; Ana, anakinra; Tac, tacrolimus; MMF, mycophenolate mofetil. BMI, body mass index; GAD65, glutamic acid decarboxylase 65; hbA1c, glycated hemoglobin; HLA, human leukocyte antigen; SUITO, secretory unit of islet transplant objects. ${ }^{a}$ Each value was evaluated when the first blood samples were drawn after islet transplantation.

and maintained high titers posttransplantation (Fig. 2B). Pt. \#6, who experienced immediate graft function loss, rapidly developed GAD65-Ab after transplantation. Pt. \#5, who restarted insulin injection at 63 weeks after transplantation due to chronic graft dysfunction, showed GAD65-Ab transiently at weeks 77-90 (Fig. 2B). Pts. \#2 and \#3, who maintained long-term graft survival, remained negative for serum GAD65-Ab at all the time points (Fig. 2A).

Thus, three of the three patients who developed acute or chronic graft dysfunction showed serum GAD65-Ab at multiple time points posttransplantation.

\section{GAD65-Specific T-Cells in Islet Transplantation}

To determine the type and breadth of GAD65specific T-cells after islet transplantation, we cultured PBMCs obtained from patients with pools of GAD65 overlapping peptides (14 peptide clusters; C1-C14). To expand the peptide-reactive T-cells, IL-2 was added to cultures at day 2 and day 5. Cultured cells were harvested at day 7 and restimulated with the same GAD65 peptides for $24 \mathrm{~h}$ to measure cytokine production by the expanded specific T-cells (Fig. 3). PBMCs were obtained from Pts. \#1-5 when islet graft functions were still maintained (Fig. 1). In three patients, Pts. \#1, $\# 2$, and \#3, who maintained long-term graft survival, cytokine secretion in response to GAD65 peptides was very limited, and only a few peptide clusters induced cytokine secretion (Fig. 3A, B). This observation suggests that the repertoire of GAD65-specific T-cells in these patients was limited, and the frequency of these cells in peripheral blood was low. In contrast, in Pts. \#4 and \#5, who developed chronic graft dysfunction at late phase, multiple cytokines were robustly secreted in response to multiple GAD65 peptide clusters, suggesting the presence of a broad repertoire of GAD65specific T-cells. Expanded GAD65-specific T-cells produced variable types of cytokines including type 1 (IFN- $\gamma$ ) and type 2 cytokines (IL-5 and IL-13) (Fig. 3C, D). The difference in GAD65-specific T-cell responses between long-term graft survival group and graft dysfunction group was not due to the difference in the overall T-cell reactivity, as $\mathrm{CD}^{+} \mathrm{T}$-cells stimulated with a superantigen SEB as a positive control secreted comparable levels of cytokines including IL-13 and IFN- $\gamma$ between the two groups (Fig. 4). Of note, expanded GAD65-specific T-cells did not produce IL-10 either in the long-term graft survival group (Figs. 3B, 5A) or in the chronic graft dysfunction group (Figs. 3D, 5B). This was in contrast to the secretion of IL-10 by GAD65-specific T-cells in nondiabetic healthy individuals (Fig. 5C). 

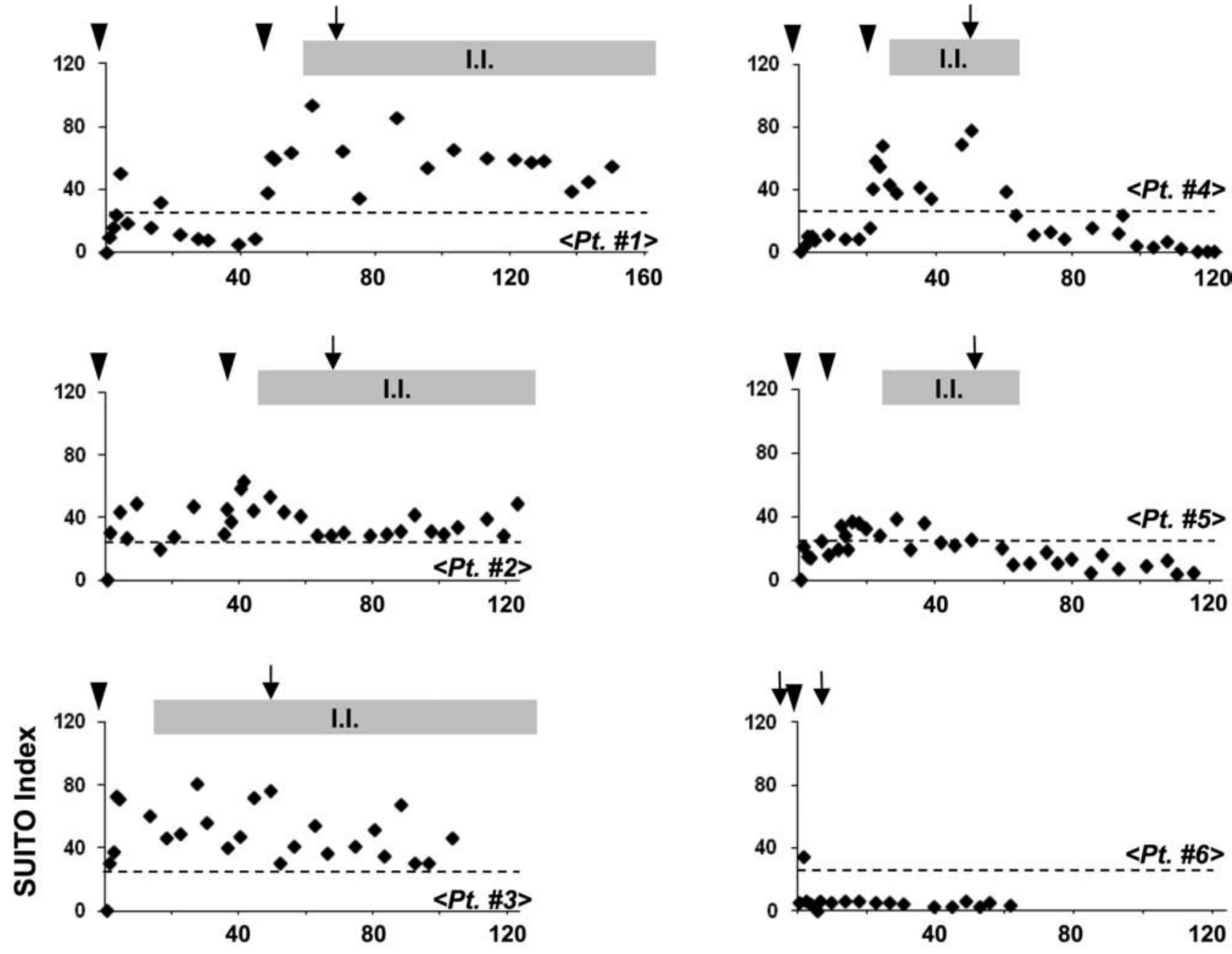

Weeks after islet transplantation

\section{$\nabla$ : Islet transplantation \\ $\downarrow:$ T-cell analysis \\ I.I. : Insulin Independence}

Figure 1. Clinical course after islet transplantation. Pts. \#1, \#2, and \#3 maintained higher secretory unit of islet transplant objects (SUITO) index and insulin independence, while Pts. \#4, \#5, and \#6 developed graft dysfunction. Glutamic acid decarboxylase 65 (GAD65)-specific T-cell responses were analyzed in Pts. \#1-5 when islet graft functions were maintained. Dotted lines indicate the reference SUITO index level (score 26.0), which reflects the borderline of insulin injection requirement. I.I., insulin independence.

To analyze the cytokine expression by GAD65-specific T-cells at a single-cell level, intracytoplasmic cytokine expression by the expanded GAD65-specific T-cells was analyzed. As GAD65 peptide cluster \#4 (C4) induced the highest magnitude of cytokine production in both Pts. \#4 and \#5 (Fig. 3C, D), we focused our analysis on the cells specific for this set of peptides. As shown in Figure 3E, GAD65specific CD4 ${ }^{+}$T-cells in Pt. \#4 dominantly expressed IFN- $\gamma$ (thus are Th1 cells), and some expressed both IFN- $\gamma$ and IL-13. GAD65-specific CD4+ T-cells in Pt. \#5 were composed of IFN- $\gamma$-expressing Th1 cells, IL-13-expressing Th2 cells, and cells coexpressing IFN- $\gamma$ and IL-13. Furthermore, both patients displayed IFN- $\gamma$-expressing GAD65-specific CD8 ${ }^{+}$T-cells (Fig. 3E). These observations show that GAD65-specific T-cells emerging after islet transplantation include both $\mathrm{CD}^{+}{ }^{+}$and $\mathrm{CD} 8^{+}$T-cells. GAD65-specific $\mathrm{CD} 4^{+}$ 

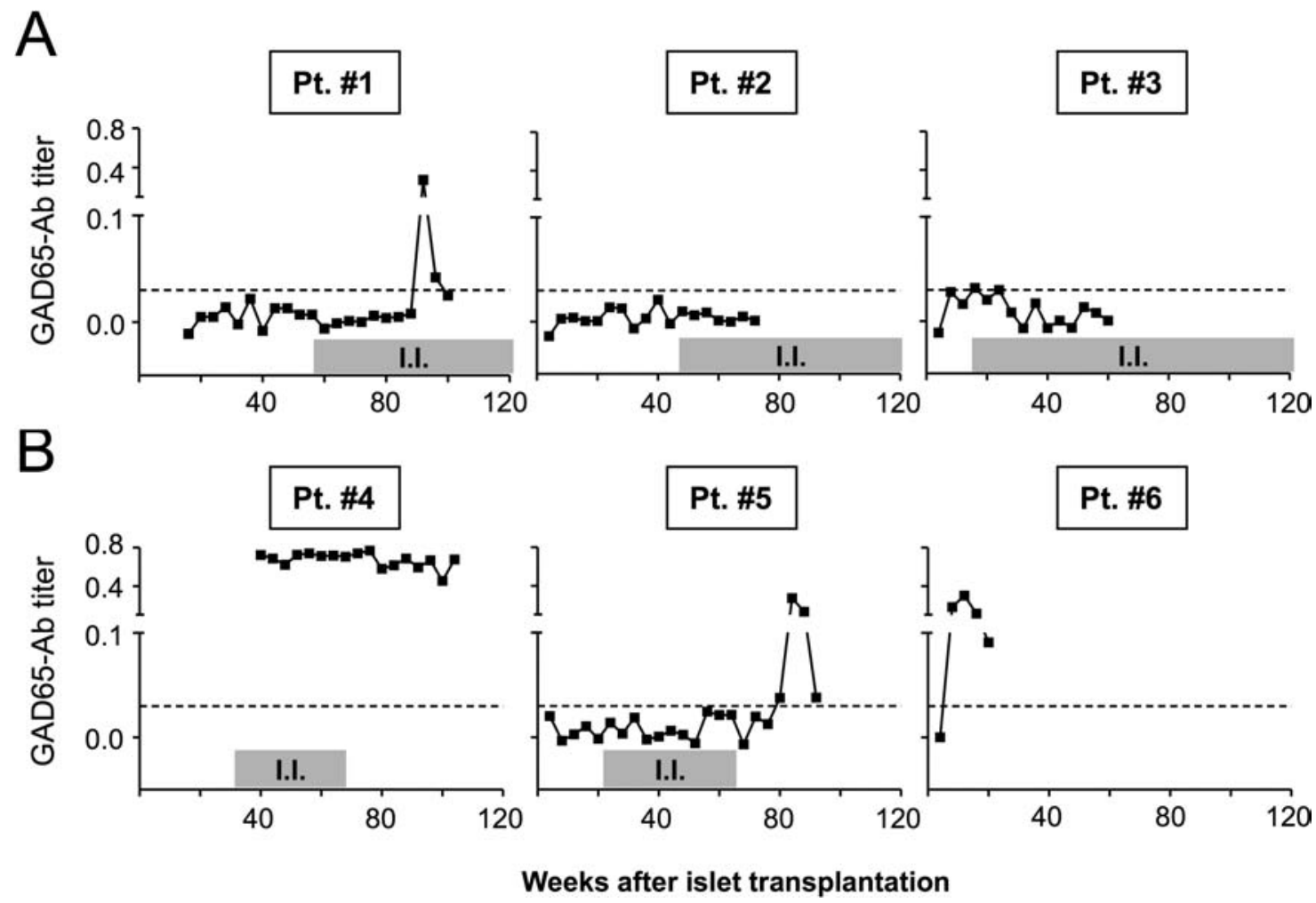

Figure 2. The kinetics of serum GAD65-Ab titers. Serum GAD65-Ab titers in patients who maintained long-term graft survival (A) and patients who developed graft dysfunction (B). Dotted lines indicate the cutoff value of the 99th percentile of normal controls. I.I., insulin independence.

T-cells were composed of heterogeneous cell populations expressing different sets of cytokines.

We were able to follow GAD65-specific T-cell responses at multiple points after islet transplantation in two patients, Pts. \#1 and \#5 (Fig. 5). Pt. \#1, who has been maintaining graft survival for more than 155 weeks, did not display strong GAD65-specific T-cell responses even at 143 weeks posttransplantation. In contrast, in Pt. \#5 who restarted insulin injection 63 weeks after the first transplantation, IFN- $\gamma$-secreting T-cells in response to GAD65 C4 peptides were detected as early as at 15 weeks. At later time points, cytokine secretion in response to GAD65 C4 increased, and secretion of cytokines other than IFN- $\gamma$, such as IL-5 and IL-13, became detectable
(Fig. 6). Thus, in Pt. \#5, the magnitude of GAD65specific T-cell response increased according to the progress of graft dysfunction, and such T-cells expressed more variable types of cytokines at late phase.

\section{A Patient With Immediate Loss of Islet Function After Transplantation Displayed Persistent GAD65-Specific CD8+ T-Cell Responses Even Under Thymoglobulin Administration}

We analyzed GAD65-specific T-cell responses in Pt. \#6 whose islet function was immediately lost after transplantation. At pretransplantation, a broad repertoire of GAD65-speficic T-cells was detectable, and multiple GAD peptide clusters, including C2, C3, C4, C5, C6, C10,

\section{FACING PAGE}

Figure 3. GAD65-specific T-cell responses in type 1 diabetes (T1D) patients after islet transplantation. T-cell responses were analyzed when islet functions were preserved. Peripheral blood mononuclear cells (PBMCs) were stimulated with GAD65 peptide clusters (C1-C14) in duplicate and cultured for 7 days in the presence of interleukin (IL)-2. Seven cytokines secreted during $24 \mathrm{~h}$ restimulation were measured by a multiplex bead-based cytokine assay. (A, C) IL-13 and interferon (IFN)- $\gamma$ secretion in patients with long-term graft survival (A) and with chronic graft dysfunction (C). Data were expressed as mean \pm SD. (B, D) Cytokine data were transformed into a heat-map format indicating the fold increase from the background. Blue indicates the strongest cytokine secretion, whereas yellow indicates the background. (E) Intracellular cytokine expression by T-cells in response to GAD65 C4 in patients who eventually developed chronic graft rejection. The expression of intracytoplasmic cytokines was analyzed by flow cytometry $6 \mathrm{~h}$ after restimulation with same peptide clusters. 


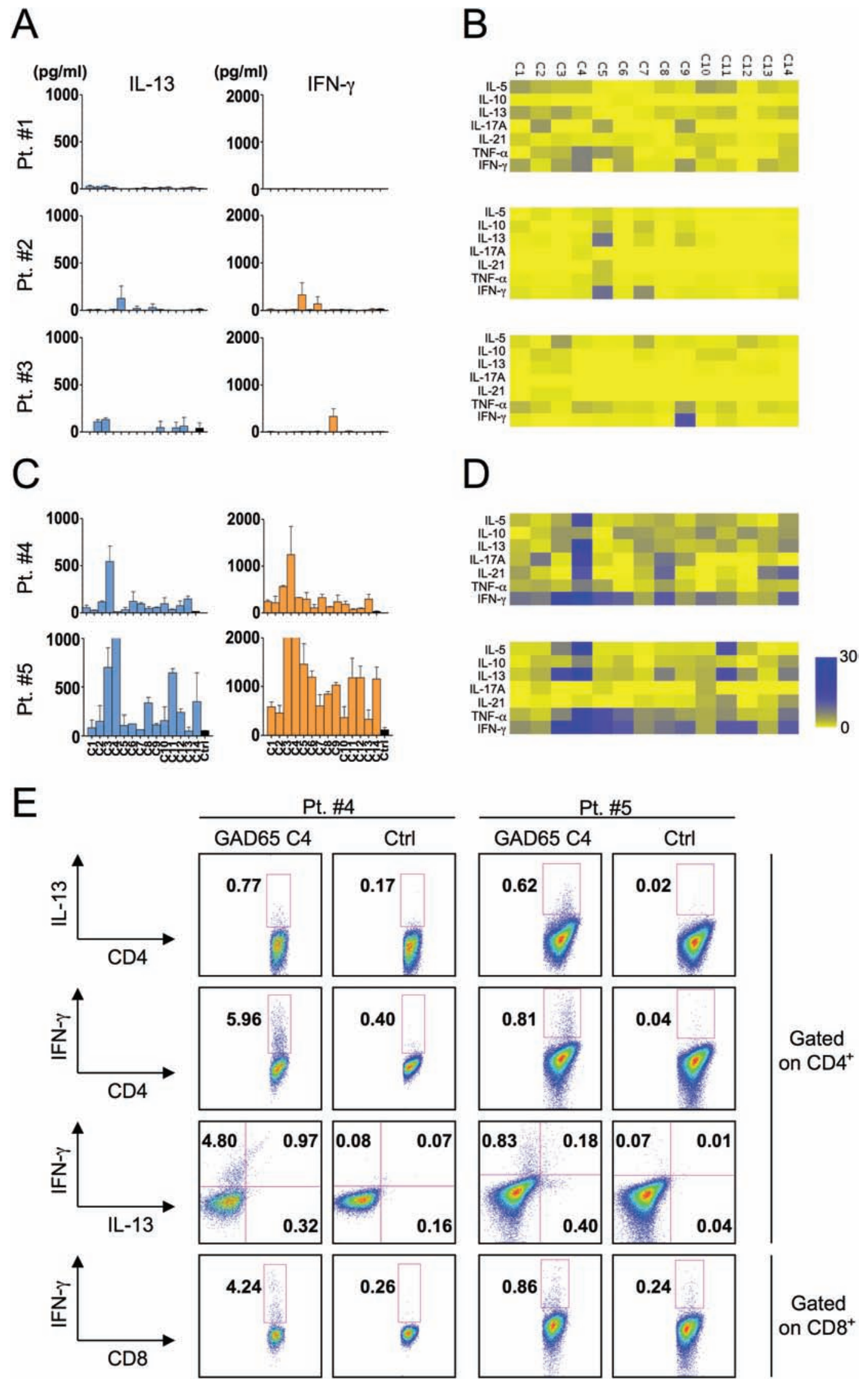



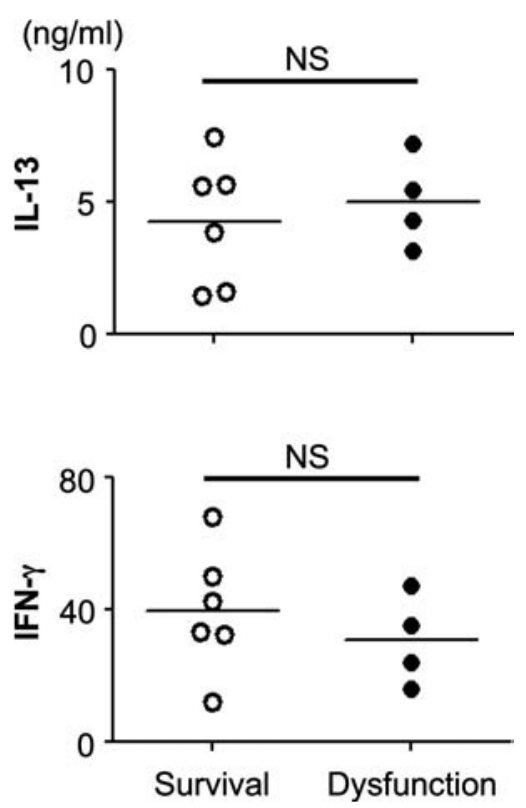

Figure 4. T-cell responses stimulated by staphylococcal enterotoxin B (SEB) in T1D patients after islet transplantation. PBMCs were stimulated with $0.1 \mu \mathrm{g} / \mathrm{ml}$ of SEB in duplicate and cultured for 7 days in the presence of IL-2. Seven cytokines secreted during $24 \mathrm{~h}$ restimulation were measured by a multiplex bead-based cytokine assay. Each value of IL-13 (A) and IFN- $\gamma$ (B) from duplicates in three long-term graft survival patients (open circle) and two graft dysfunction patients (closed circle) were plotted. NS, no significant difference assessed by Student's $t$ test.

and $\mathrm{C} 14$, induced cytokine secretion by the expanded T-cells (Fig. 7A, left; B, left). The type of cytokines secreted by the expanded GAD65-specific T-cells was variable and included IL-10, IL-13, IL-17A, and IFN- $\gamma$ (Fig. 7A, left; B, left). Intracytoplasmic cytokine detection assay showed that GAD65-specific $\mathrm{CD} 4^{+} \mathrm{T}$-cells included IFN- $\gamma$-producing Th1 cells, IL-13-producing Th 2 cells, and IL-13/IFN- $\gamma$ coexpressing cells. Moreover, IFN- $\gamma$-producing $\mathrm{CD}^{+}$T-cells were also detected specific for multiple GAD65 peptides, including C3, C6, and C14 (Fig. 7B, left).

To analyze GAD65-specific T-cell responses after islet transplantation, we obtained blood sample at 4 weeks posttransplantation. As thymoglobulin was administered for induction of immunosuppression in this patient, the frequency of T-cells in blood was very low at the sampling. Therefore, we focused our assay on the five peptide clusters (C3, C4, C5, C6, and C14), which induced cytokine responses before transplantation (Fig. 7B). At 4 weeks posttransplantation, IFN- $\gamma$ was secreted in response to C6 (Fig. 7A, right; B, right). Intracytoplasmic cytokine detection assay revealed that IFN- $\gamma$ was expressed by mostly GAD65-specific CD ${ }^{+}$ T-cells (Fig. 7B, right). Thus, GAD65-specific CD8 ${ }^{+}$
T-cells were present in this patient even when the total blood T-cell number was low.

\section{DISCUSSION}

In this study, we analyzed the breadth and type of GAD65-specific T-cell responses in T1D patients after allogeneic islet transplantation. GAD65-specific T-cells were barely detected in three of three long-term graft survivors, whereas GAD65-specific CD8 ${ }^{+} \mathrm{T}$-cells were detected in three of three patients with acute or chronic graft dysfunction. A longitudinal analysis in a patient with chronic graft dysfunction showed an increase of the magnitude and the type of GAD65-specific T-cells during the clinical course. These results suggest that the emergence of proinflammatory T-cells specific for islet antigens is associated with chronic graft dysfunction in islet transplantation in T1D. Consistently, involvement of autoreactive immunity in chronic graft failure has also been demonstrated in mouse transplantation models of heart (29) and skin (32), as well as in human organ transplantations, including liver transplantation for autoimmune liver diseases $(6,8,15,34)$ and whole pancreas transplantation for T1D (13,16,33). Importantly, our study showed that GAD65-specific T-cell responses became detectable when patients were still maintaining graft function and insulin independence and preceded the occurrence of chronic graft dysfunction. Therefore, analysis of islet antigen-specific T-cell repertoires might be useful to predict impending chronic graft dysfunction after islet transplantation.

Our study also suggests that GAD65-specific CD4 ${ }^{+}$ T-cells emerging in chronic graft dysfunction patients are heterogeneous and composed of populations that differentially express IFN- $\gamma$ and type 2 cytokines, including IL-5 and IL-13. Given that IFN- $\gamma$ is involved in the development of T1D $(9,25)$, IFN- $\gamma$ likely plays a pathogenic role also in chronic graft dysfunction. In contrast, the role of type 2 cytokines in chronic graft dysfunction is unclear. A previous study shows that insulin-specific T-cell clones established from pancreatic lymph nodes of T1D patients preferentially secreted IL-13, but not IFN- $\gamma$ (14). Therefore, type 2 cytokines might also contribute to the destruction of transplanted islet grafts. On the contrary, it is possible that type 2 cytokines play an antiinflammatory role. For example, a systemic administration of recombinant IL-13 prevents the onset of diabetes in non-obese diabetic (NOD) mice (41). Furthermore, generation of IL-5-producing GAD65-specific $\mathrm{CD}^{+}$ T-cells was shown to protect NOD mice from diabetes development (30).

Notably, IL-10-producing GAD65-specific CD4 ${ }^{+}$ T-cells were not detected in any patients posttransplantation. This was not due to technical limitation in our 
A

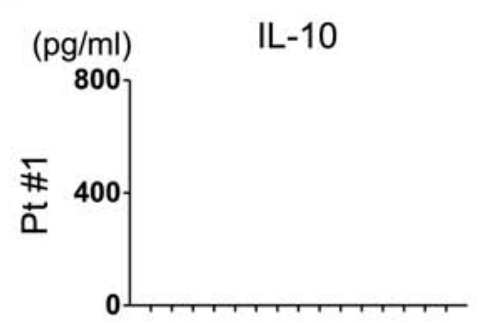

C
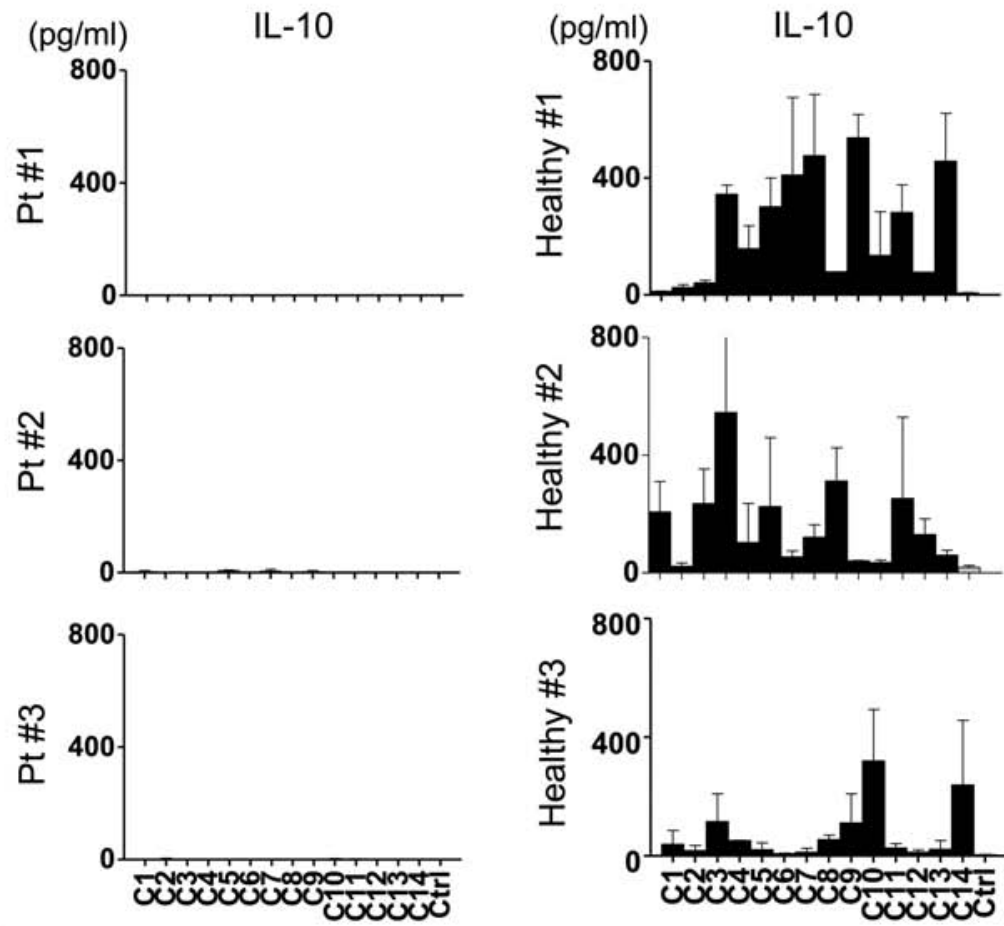

B
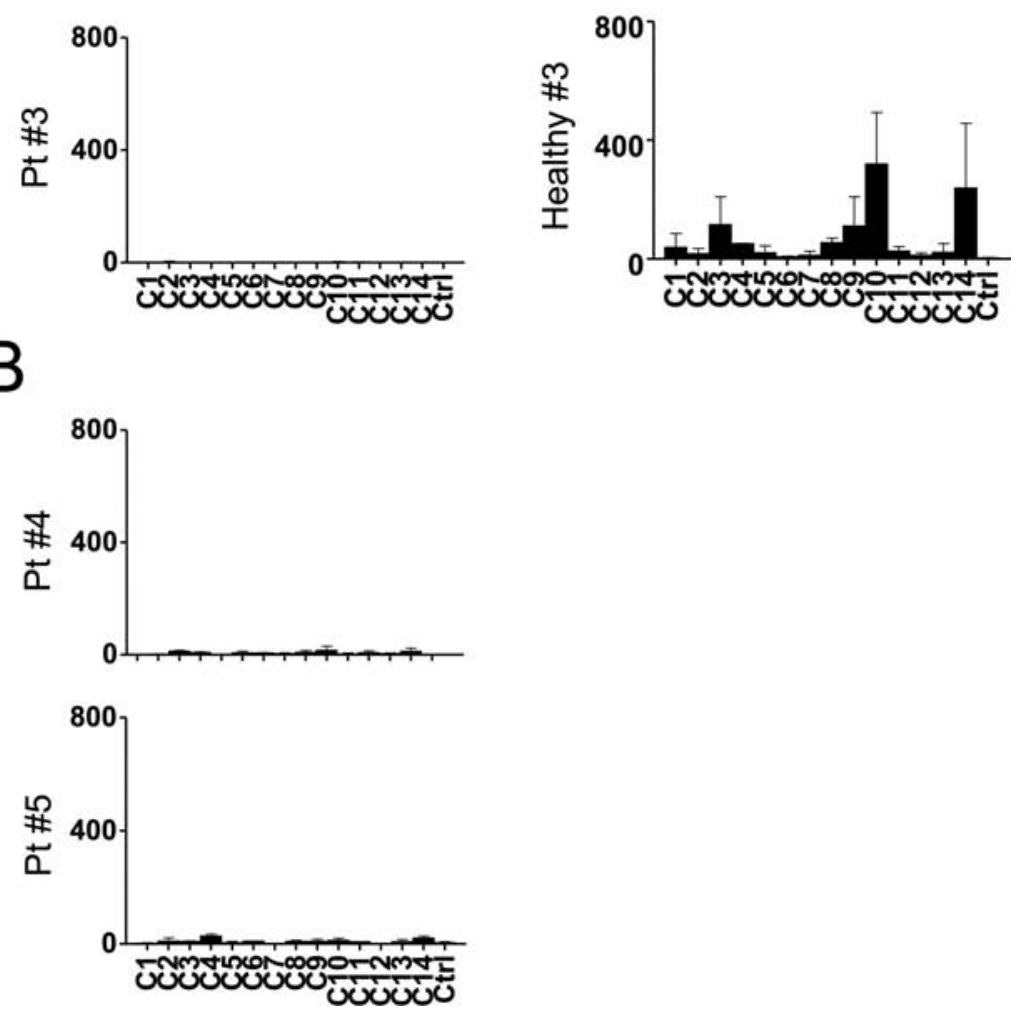

Figure 5. GAD65-specific IL-10 responses in T1D patients who maintained long-term graft survival (A), T1D patients who eventually developed chronic graft dysfunction (B), and nondiabetic healthy individuals (C). PBMCs were stimulated with GAD65 peptide clusters (C1-C14) and cultured for 7 days in the presence of IL-2. IL-10 secreted during $24 \mathrm{~h}$ restimulation was measured.

assays, as IL-10-producing GAD65-specific T-cells were detected in samples from healthy individuals as well as from a T1D patient (Pt. \#6 at pretransplantation). While such IL-10-producing T-cells might act as regulators of proinflammatory effector T-cells $(2,31)$, our data suggest that chronic graft dysfunction is associated more with the development of proinflammatory islet antigen-specific
T-cells rather than the failure of development of IL-10producing regulatory $\mathrm{T}$-cells.

When compared to GAD65-specific T-cell assay, the correlation between serum GAD65-Ab titers and insulin independency was not so clear-cut in our study, at least partly due to transient GAD65-Ab appearance in sera in several patients. Transient development of autoantibodies 


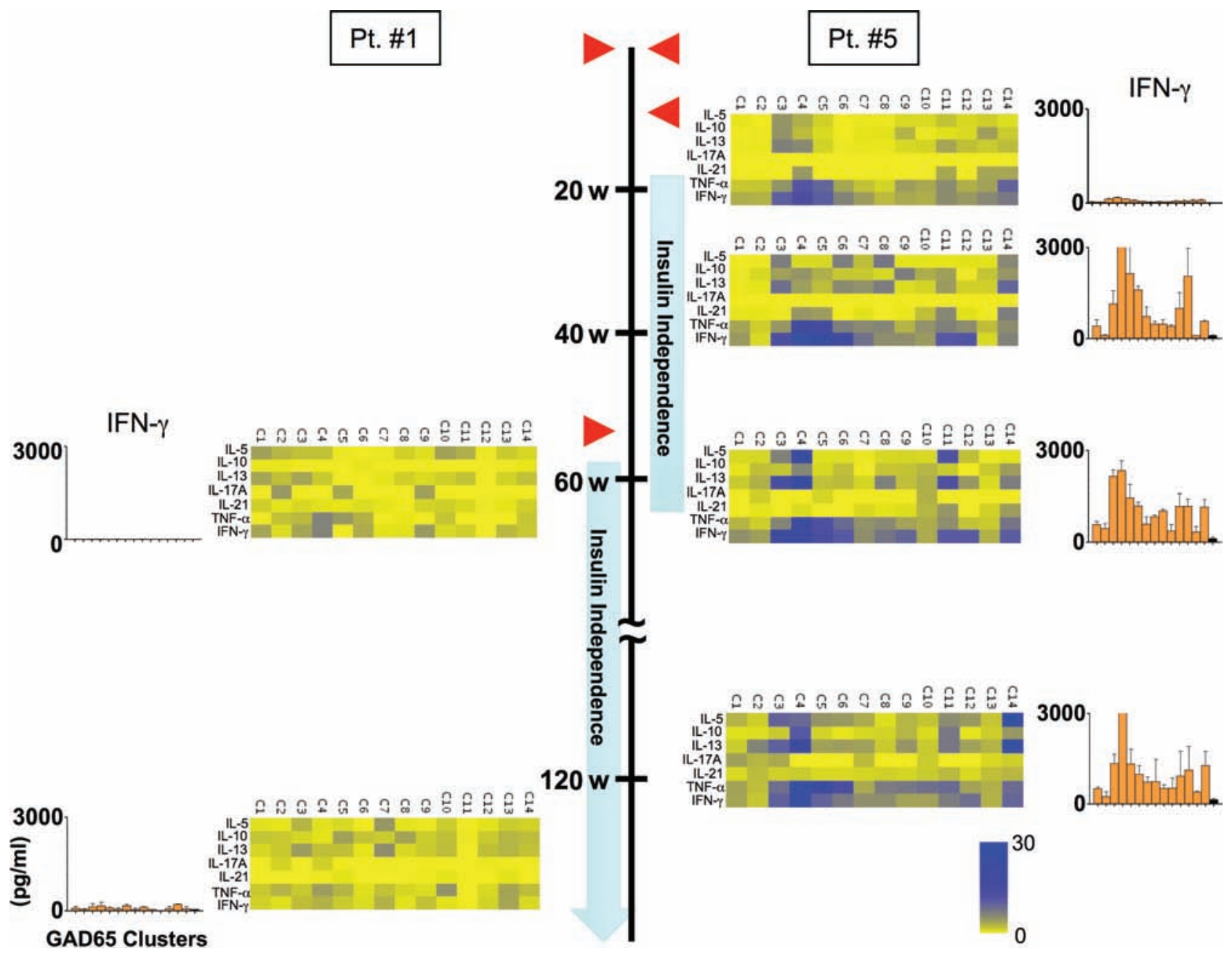

Figure 6. Longitudinal analysis of GAD65-specific T-cell responses. GAD65-specific T-cell responses were analyzed at different time points after transplantation by multiplex bead-based cytokine assays. Pt. \#1 maintained long-term graft survival, whereas Pt. \#5 developed chronic graft dysfunction at 46 weeks after the second transplantation. Fold increase of cytokine levels from the background is shown in a heat-map format. Each patient received islet transplantation twice shown by red triangles. w, weeks after the first islet transplantation.

specific for islet antigens including GAD65 is observed even in healthy subjects without association with the risk of onset of T1D (11), and the mechanism of their development is unknown. Thus, measurement of serum GAD65-Ab alone may not be sufficient to predict the clinical outcome. Measurement of multiple islet autoantibodies at multiple time points posttransplantation might provide a better biomarker in this context, as shown previously $(5,12,28)$.

A limitation of this study was the lack of a pretransplant analysis except in one patient. Therefore, whether GAD65-specific T-cells detected posttransplantation are derived from preexisting repertoire or newly developed after transplantation is unknown. A systematic comparison regarding islet-antigen specific
T-cell repertoires between before and after transplantation should reveal their developmental mechanism after transplantation.

In conclusion, our study supports the hypothesis that development of islet antigen-specific T-cell immunity is associated with chronic islet graft dysfunction after allogeneic islet transplantation. A larger-scale study should reveal the efficiency of analysis of islet antigenspecific T-cells in the prediction of clinical outcomes. Importantly, such study might provide insights in the development of novel approach to prevent chronic islet graft dysfunction. Successful immunosuppressive therapy against these antigen-specific T-cells may prolong islet function and survival in allotransplantation for T1D recipients. 
A
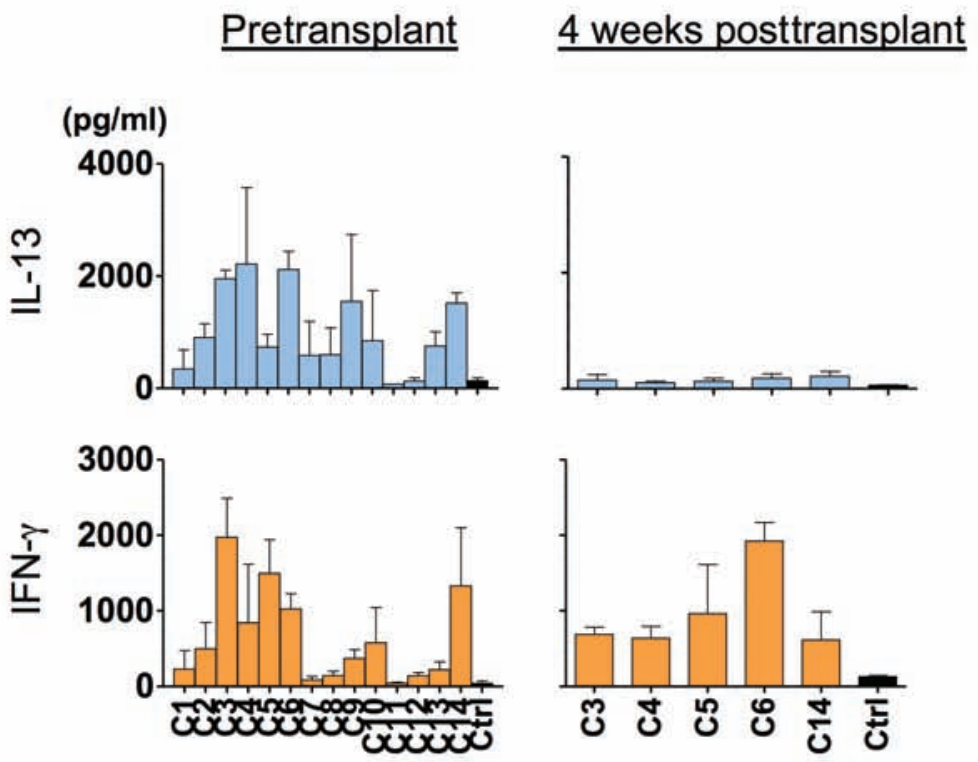

\section{GAD65 Clusters}

B

\section{Pretransplant}

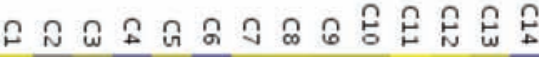
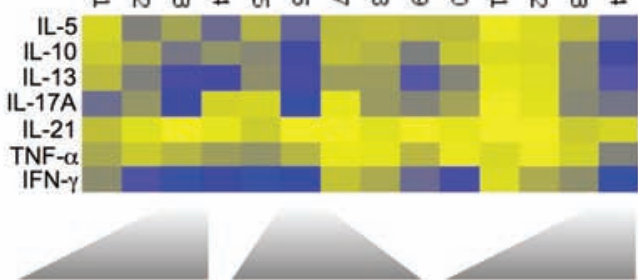

C3

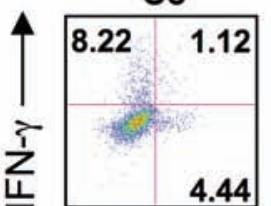

IL-13

$\frac{1}{4}$

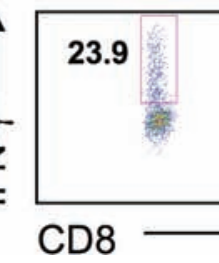

\section{4 weeks posttransplant}
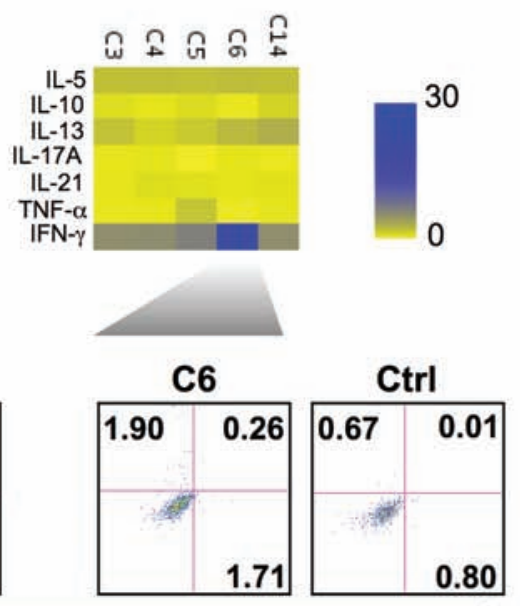

Gated on CFSE-CD4 ${ }^{+}$

Figure 7. GAD65-specific T-cell responses in a patient whose islet function was immediately lost after transplantation. T-cell responses were analyzed before and 4 weeks after islet transplantation. Carboxyfluorescein succinimidyl ester (CFSE)-labeled PBMCs were stimulated with GAD65 peptide clusters (C1-C14) in duplicate and cultured for 7 days in the presence of IL-2. Seven cytokines secreted during $24 \mathrm{~h}$ restimulation were measured. IL-13 and IFN- $\gamma$ responses before and 4 weeks after islet transplantation are shown in (A). Data were expressed as mean \pm SD. Fold increase of cytokine levels from the background is shown in a heat-map format (B, top). The expression of intracytoplasmic cytokines was analyzed by flow cytometry $6 \mathrm{~h}$ after restimulation with same peptide clusters (B, bottom). Gated to CFSE-negative (thus proliferating) $\mathrm{CD}^{+}{ }^{+}$or $\mathrm{CD} 8^{+} \mathrm{T}-$ cell populations. 
ACKNOWLEDGMENTS: This research was supported by the proceedings of the W.W. Caruth, Jr., Chair for Organ Transplantation Immunology and All Saints Health Foundation. While we fully acknowledge Dr. Matsumoto's contributions and tremendous expertise in this field, and while we in no way want to diminish his accomplishments, this work was conceived, executed, and disseminated by the Baylor Research Institute, and any further communication about this work should be directed to the Institute and its current members and not past members. The authors declare no conflicts of interest.

\section{REFERENCES}

1. Alejandro, R.; Barton, F. B.; Hering, B. J.; Wease, S. Collaborative Islet Transplant Investigators. 2008 Update from the collaborative islet transplant registry. Transplantation 86:1783-1788; 2008.

2. Arif, S.; Tree. T. I.; Astill, T. P.; Tremble, J. M.; Bishop, A. J.; Dayan, C. M.; Roep, B. O.; Peakman, M. Autoreactive $\mathrm{T}$-cell responses show proinflammatory polarization in diabetes but a regulatory phenotype in health. J. Clin. Invest. 113:451-463; 2004.

3. Atkinson, M. A.; Eisenbarth, G. S. Type 1 diabetes: New perspectives on disease pathogenesis and treatment. Lancet 358:221-229; 2001.

4. Baekkeskov, S.; Aanstoot, H. J.; Christgau, S.; Reetz, A.; Solimena, M.; Cascalho, M.; Folli, F.; Richter-Olesen, H.; De Camilli, P. Identification of the $64 \mathrm{~K}$ autoantigen in insulindependent diabetes as the GABA-synthesizing enzyme glutamic acid decarboxylase. Nature 347:151-156; 1990.

5. Bosi, E.; Braghi, S.; Maffi, P.; Scirpoli, M.; Bertuzzi, F.; Pozza, G.; Secchi, A.; Bonifacio, E. Autoantibody response to islet transplantation in type 1 diabetes. Diabetes 50: 2464-2471; 2001.

6. Czaja, A. J. Autoimmune hepatitis after liver transplantation and other lessons of self-intolerance. Liver Transpl. $8: 505-513 ; 2002$.

7. Di Lorenzo, T. P.; Peakman, M.; Roep, B. O. Translational mini-review series on type 1 diabetes: Systematic analysis of T-cell epitopes in autoimmune diabetes. Clin. Exp. Immunol. 148:1-16; 2007.

8. Duclos-Vallee, J. C.; Sebagh, M. Recurrence of autoimmune disease, primary sclerosing cholangitis, primary biliary cirrhosis, and autoimmune hepatitis after liver transplantation. Liver Transpl. 15:S25-34; 2009.

9. Eizirik, D. L.; Colli, M. L.; Ortis, F. The role of inflammation in insulitis and beta-cell loss in type 1 diabetes. Nat. Rev. Endocrinol. 5:219-226; 2009.

10. Gianani, R.; Eisenbarth, G. S. The stages of type 1A diabetes: 2005. Immunol. Rev. 204:232-249; 2005.

11. Gullstrand, C.; Wahlberg, J.; Ilonen, J.; Vaarala, O.; Ludvigsson, J. Progression to type 1 diabetes and autoantibody positivity in relation to HLA-risk genotypes in children participating in the ABIS study. Pediatr. Diabetes 9:182-190; 2008.

12. Huurman, V. A.; Hilbrands, R.; Pinkse, G. G.; Gillard, P.; Duinkerken, G.; van de Linde, P.; van der Meer-Prins, P. M.; Versteeg-van der Voort Maarschalk, M. F.; Verbeeck, K.; Alizadeh, B. Z.; Mathieu, C.; Gorus, F. K.; Roelen, D. L.; Claas, F. H.; Keymeulen, B.; Pipeleers, D. G.; Roep, B. O. Cellular islet autoimmunity associates with clinical outcome of isleT-cell transplantation. PLoS One 3:e2435, 2008.
13. Ishida-Oku, M.; Iwase, M.; Sugitani, A.; Masutani, K.; Kitada, H.; Tanaka, M.; Iida, M. A case of recurrent type 1 diabetes mellitus with insulitis of transplanted pancreas in simultaneous pancreas-kidney transplantation from cardiac death donor. Diabetologia 53:341-345; 2010.

14. Kent, S. C.; Chen, Y.; Bregoli, L.; Clemmings, S. M.; Kenyon, N. S.; Ricordi, C.; Hering, B. J.; Hafler, D. A. Expanded T-cells from pancreatic lymph nodes of type 1 diabetic subjects recognize an insulin epitope. Nature 435:224-228; 2005.

15. Kerkar, N.; Hadzić, N.; Davies, E. T.; Portmann, B.; Donaldson, P. T.; Rela, M.; Heaton, N. D.; Vergani, D.; Mieli-Vergani, G. De-novo autoimmune hepatitis after liver transplantation. Lancet 351:409-413; 1998.

16. Laughlin, E.; Burke, G.; Pugliese, A.; Falk, B.; Nepom, G. Recurrence of autoreactive antigen-specific $\mathrm{CD}^{+} \mathrm{T}$-cells in autoimmune diabetes after pancreas transplantation. Clin. Immunol. 128:23-30; 2008.

17. Mallone, R.; Kochik, S. A.; Laughlin, E. M.; Gersuk, V. H.; Reijonen, H.; Kwok, W. W.; Nepom, G. T. Differential recognition and activation thresholds in human autoreactive GAD-specific T-cells. Diabetes 53:971-977; 2004.

18. Matsumoto, S.; Noguchi, H.; Hatanaka, N.; Shimoda, M.; Kobayashi, N.; Jackson, A.; Onaca, N.; Naziruddin, B.; Levy, M. F. SUITO index for evaluation of efficacy of single donor islet transplantation. Cell Transplant. 18:557-562; 2009.

19. Matsumoto, S.; Noguichi, H.; Shimoda, M.; Ikemoto, T.; Naziruddin, B.; Jackson, A.; Tamura, Y.; Olson, G.; Fujita, Y.; Chujo, D.; Takita, M.; Kobayashi, N.; Onaca, N.; Levy, M. Seven consecutive successful clinical islet isolations with pancreatic ductal injection. Cell Transplant. 19:291-297; 2010.

20. Matsumoto, S.; Takita, M.; Chaussabel, D.; Noguchi, H.; Shimoda, M.; Sugimoto, K.; Itoh, T.; Chujo, D.; SoRelle, J.; Onaca, N.; Naziruddin, B.; Levy, M. F. Improving efficacy of clinical islet transplantation with iodixanol based islet purification, thymoglobulin induction and blockage of IL-1 beta and TNF-alpha. Cell Transplant. 20:1641-1647; 2011.

21. Matsumoto, S.; Yamada, Y.; Okitsu, T.; Iwanaga, Y.; Noguchi, H.; Nagata, H.; Yonekawa, Y.; Nakai, Y.; Ueda, M.; Ishii, A.; Yabunaka, E.; Tanaka, K. Simple evaluation of engraftment by secretory unit of islet transplant objects (SUITO) for living donor and cadaveric donor fresh or cultured islet transplantation. Transplant. Proc. 37:3435-3437; 2005.

22. Pinkse, G. G.; Tysma, O. H.; Bergen, C. A.; Kester, M. G.; Ossendorp, F.; van Veelen, P. A.; Keymeulen, B.; Pipeleers, D.; Drijfhout, J. W.; Roep, B. O. Autoreactive CD8 T-cells associated with beta cell destruction in type 1 diabetes. Proc. Natl. Acad. Sci. USA 102:18425-18430; 2005.

23. Reijonen, H.; Novak, E. J.; Kochik, S.; Heninger, A.; Liu, A. W.; Kwok, W. W.; Nepom, G. T. Detection of GAD65specific T-cells by major histocompatibility complex class II tetramers in type 1 diabetic patients and at-risk subjects. Diabetes 51:1375-1382; 2002.

24. Roep, B. O. T-cell responses to autoantigens in IDDM. The search for Holy Grail. Diabetes 45:1147-1156; 1996.

25. Roep, B. O. The role of T-cells in the pathogenesis of type 1 diabetes: From cause to cure. Diabetologia 46:305$321 ; 2003$.

26. Roep, B. O.; Stobbe, I.; Duinkerken, G.; van Rood, J. J.; Lernmark, A.; Keymeulen, B.; Pipeleers, D.; Claas, F. H.; de Vries, R. R. Auto- and alloimmune reactivity to human islet allografts transplanted into type 1 diabetic patients. Diabetes 48:484-490; 1999. 
27. Ryan, E. A.; Paty, B. W.; Senior, P. A.; Bigam, D.; Alfadhli, E.; Kneteman, N. M.; Lakey, J. R.; Shapiro, A. M. Fiveyear follow-up after clinical islet transplantation. Diabetes 54:2060-2069; 2005.

28. Shapiro, A. M.; Ricordi, C.; Hering, B. J.; Auchincloss, H.; Lindblad, R.; Robertson, R. P.; Secchi, A.; Brendel, M. D.; Berney, T.; Brennan, D. C.; Cagliero, E.; Alejandro, R.; Ryan, E. A.; DiMercurio, B.; Morel, P.; Polonsky, K. S.; Reems, J. A.; Bretzel, R. G.; Bertuzzi, F.; Froud, T.; Kandaswamy, R.; Sutherland, D. E.; Eisenbarth, G.; Segal, M.; Preiksaitis, J.; Korbutt, G. S.; Barton, F. B.; Viviano, L.; Seyfert-Margolis, V.; Bluestone, J.; Lakey, J. R. International trial of the Edmonton protocol for islet transplantation. N. Engl. J. Med. 355:1318-1330; 2006.

29. Tanaka, M.; Zwierzchoniewska, M.; Mokhtari, G. K.; Terry, R. D.; Balsam, L. B.; Robbins, R. C.; Fedoseyeva, E. V. Progression of alloresponse and tissue-specific immunity during graft coronary artery disease. Am. J. Transplant. 5:1286-1296; 2005.

30. Tian, J.; Atkinson, M. A.; Clare-Salzler, M.; Herschenfeld, A.; Forsthuber, T.; Lehmann, P. V.; Kaufman, D. L. Nasal administration of glutamate decarboxylase (GAD65) peptides induces Th2 responses and prevents murine insulindependent diabetes. J. Exp. Med. 183:1561-1567; 1996.

31. Tree, T. I.; Lawson, J.; Edwards, H.; Skowera, A.; Arif, S.; Roep, B. O.; Peakman, M. Naturally arising human CD4 T-cells that recognize islet autoantigens and secrete interleukin-10 regulate proinflammatory T-cell responses via linked suppression. Diabetes 59:1451-1460; 2010.

32. Valujskikh, A.; Fedoseyeva, E.; Benichou, G.; Heeger, P. S. Development of autoimmunity after skin graft rejection via an indirect alloresponse. Transplantation 73:1130-1137; 2002.

33. Vendrame, F.; Pileggi, A.; Laughlin, E.; Allende, G.; MartinPagola, A.; Molano, R. D.; Diamantopoulos, S.; Standifer, N.; Geubtner, K.; Falk, B. A.; Ichii, H.; Takahashi, H.; Snowhite, I.; Chen, Z.; Mendez, A.; Chen, L.; Sageshima, J.; Ruiz, P.; Ciancio, G.; Ricordi, C.; Reijonen, H.; Nepom, G. T.; Burke, 3rd, G. W.; Pugliese, A. Recurrence of type 1 diabetes after simultaneous pancreas-kidney transplantation, despite immunosuppression, is associated with autoantibodies and pathogenic autoreactive CD4 T-cells. Diabetes 59:947-957; 2010.

34. Vergani, D.; Mieli-Vergani, G. Autoimmunity after liver transplantation. Hepatology 36:271-276; 2002.

35. Videbaek, N.; Harach, S.; Phillips, J.; Hutchings, P.; Ozegbe, P.; Michelsen, B. K.; Cooke, A. An islet-homing NOD CD8 ${ }^{+}$cytotoxic T-cell clone recognizes GAD65 and causes insulitis. J. Autoimmun. 20:97-109; 2003.

36. Viglietta, V.; Kent, S. C.; Orban, T.; Hafler, D. A. GAD65reactive T-cells are activated in patients with autoimmune type 1a diabetes. J. Clin. Invest. 109:895-903; 2002.

37. Wang, J.; Miao, D.; Babu, S.; Yu, J.; Barker, J.; Klingensmith, G.; Rewers, M.; Eisenbarth, G. S.; Yu, L. Prevalence of autoantibody-netagive diabetes is not rare at all ages and increases with older age and obesity. J. Clin. Endocrinol. Metab. 92:88-92; 2007.

38. Wen, L.; Wong, F. S.; Burkly, L.; Altieri, M.; Mamalaki, C.; Kioussis, D.; Flavell, R. A.; Sherwin, R. S. Induction of insulitis by glutamic acid decarboxylase peptide-specific and HLA-DQ8-restricted CD4 ${ }^{+}$T-cells from human DQ transgenic mice. J. Clin. Invest. 102:947-957; 1998.

39. Wong, F. S.; Janeway, Jr., C. A. The role of CD4 vs. CD8 T-cells in IDDM. J. Autoimmun. 13:290-295; 1999.

40. Yu, L.; Rewers, M.; Gianani, R.; Kawasaki, E.; Zhang, Y.; Verge, C.; Chase, P.; Klingensmith, G.; Erlich, H.; Norris, J.; Eisenbarth, G. S. Antiislet autoantibodies usually develop sequentially rather than simultaneously. J. Clin. Endocrinol. Metab. 81:4264-4267; 1996.

41. Zaccone, P.; Phillips, J.; Conget, I.; Gomis, R.; Haskins, K.; Minty, A.; Bendtzen, K.; Cooke, A.; Nicoletti, F. Interleukin-13 prevents autoimmune diabetes in NOD mice. Diabetes 48:1522-1528; 1999.

42. Zekzer, D.; Wong, F. S.; Ayalon, O.; Millet, I.; Altieri, M.; Shintani, S.; Solimena, M.; Sherwin, R. S. GAD-reactive $\mathrm{CD}^{+}{ }^{+}$Th1 cells induce diabetes in NOD/SCID mice. J. Clin. Invest. 101:68-73; 1998. 